\title{
STUDI KEGAGALAN PADA TIANG BOR TERINSTRUMENTASI PADA PROYEK DI KAWASAN SUDIRMAN
}

\author{
Nurdiyanto Surya G.P. ${ }^{1}$, Sunarjo Leman ${ }^{2}$, dan Ali Iskandar ${ }^{3}$ \\ ${ }^{I}$ Program Studi Sarjana Teknik Sipil, Universitas Tarumanagara, Jl. Letjen S. Parman No.1 Jakarta \\ Email: nurdianto12345@gmail.com \\ ${ }^{2}$ Program Studi Sarjana Teknik Sipil, Universitas Tarumanagara, Jl. Letjen S. Parman No.1 Jakarta \\ Email: sunarjo@ft.untar.ac.id \\ ${ }^{3}$ Program Studi Sarjana Teknik Sipil, Universitas Tarumanagara, Jl. Letjen S. Parman No.1 Jakarta \\ Email: ali.iskandar1999@gmail.com
}

\begin{abstract}
ABSTRAK
Fondasi merupakan suatu bagian struktur yang sangat penting dan krusial dalam suatu bangunan konstruksi. Dalam perencanaannya fondasi tiang bor harus memenuhi dua kriteria yang sangat penting, yaitu penurunan dan daya dukung tanah. Suatu tiang bor dapat dipasang suatu instrumen untuk mengetahui regangan atau strain yang terjadi pada saat tiang dibebani dimana regangan atau strain yang dihasilkan dapat menghasilkan nilai gaya beban atau daya dukung yang dapat dibandingkan dengan perhitungan daya dukung secara teoritis. Jenis instrumen yang biasa dipakai adalah VWSG dan Tell Tale Extensometer, yang dibahas dalam karya ilmiah ini adalah VWSG yang merupakan suatu instrumen yang berguna untuk mengetahui distribusi beban dan perilaku tiang pada saat tiang dibebani. Peran polimer sangat penting dalam pelaksanaan pembuatan fondasi tiang bor, karena berguna untuk menstabilisasikan lereng agar tidak longsor. Kegagalan tiang fondasi terkadang masih dapat ditemui dalam suatu konstruksi gedung, peninjauan yang dapat dilakukan untuk menganalisis kegagalan yang terjadi yaitu dengan meninjau kondisi parameter tanah pada lokasi proyek tersebut, memodelkan kondisi tiang dengan melihat perilaku interface antara tanah dengan polimer dan dengan beton dengan tiga beban normal yang berbeda berdasarkan percobaan praktikum direct shear test, dan menguji integritas tiang tersebut. Berdasarkan analisis yang dilakukan didapat suatu kesimpulan mengenai penyebab kegagalan tiang yang ditinjau.
\end{abstract}

Kata kunci: tiang bor, polimer, VWSG, direct shear, interface

\section{PENDAHULUAN}

\section{Latar Belakang}

Keadaan suatu kondisi tanah di suatu daerah pasti akan selalu berbeda-beda, dan jenis setiap tanah akan sangat bervariasi dan tidak mungkin akan sama setiap parameter-parameternya. Suatu tanah dapat dikatakan bersifat keras, sedang, maupun lunak harus berdasarkan data-data penyelidikan tanah yang jelas. Maka dari itu suatu data kondisi tanah akan sangat dibutuhkan dalam merancang suatu bangunan. Dari data-data yang telah didapat, data tersebut akan berguna untuk menghitung daya dukung tanah. Sehingga akan dapat diketahui kekuatan yang dapat diberikan atau dibebankan pada tanah tersebut.

Dalam perencanaan fondasi suatu bangunan, fondasi tersebut harus memenuhi 2 kriteria, yaitu penurunan dan daya dukung tanah. Pada prinsipnya fondasi tiang digunakan untuk memindahkan beban aksial ke lapisan tanah dibawahnya pada suatu kedalaman tertentu, dan fondasi tiang digunakan untuk memberikan perlawanan gaya lateral (horisontal). Pemeriksaan dengan menguji dan melakukan percobaan pembebanan dapat digunakan untuk memastikan bahwa fondasi dapat memikul beban tersebut.

Kegagalan pada tiang fondasi masih dapat ditemui di suatu bangunan konstruksi gedung. Pada suatu proyek gedung di Sudirman, tiang fondasi boredpile mengalami kegagalan yaitu loosening pada friksi tiang boredpile yang dimana nilai hasil loading test di lapangan yang didapatkan berbeda drastis dengan hasil perilaku tiang bor sebenarnya.

Pengujian dengan instrumen pada tiang berguna untuk mengetahui perilaku distribusi beban dari tiang fondasi terhadap tanah. Suatu analisis parameter tanah akan diperlukan dalam penulisan karya ilmiah ini, yang dimana parameter-parameter yang telah dianalisis dapat digunakan untuk mencari dan menganalisis kondisi tiang boredpile terinstrumen dan menduga mengapa tiang boredpile tersebut dapat drop pada proyek tersebut. Untuk mempermudah penulis dalam menganalisis kondisi fondasi tiang tersebut, penulis menggunakan program untuk menganalisis dan mensimulasikan lapisan-lapisan tanah pada fondasi tiang secara efisien dan baik. 


\section{Batasan masalah}

Adapun batasan masalah yang akan dibahas adalah:

1. Lokasi dari proyek yang akan dianalisis dalam skripsi ini berkawasan di Sudirman, DKI Jakarta.

2. Analisis parameter-parameter tanah dari data proyek.

3. Hasil instrumentasi dari VSWG.

4. Fondasi tiang bor pada konstruksi bangunan ini memiliki diameter $1200 \mathrm{~mm}$.

5. Polimer yang digunakan $\pm 120 \mathrm{MEV}$.

6. Kedalaman pengeboran tiang bor ada yang 72.7 meter

7. Analisa dan pemodelan tiang bor sebagai tiang tunggal dengan bantuan program.

8. Pengujian laboratorium berupa direct shear Consolidated Drained dengan multistages untuk 4 macam kondisi sampel.

\section{Rumusan Masalah}

Rumusan masalah yang akan dibahas adalah:

1. Bagaimana interpretasi hasil bacaan instrumentasi VWSG pada tiang bor dalam kasus ini?

2. Bagaimana kondisi tiang dengan melakukan pengujian laboratorium?

3. Apakah penyebab kegagalan pada tiang bor pada kasus ini berdasarkan analisis-analisis yang dilakukan?

\section{Tujuan Penelitian}

Tujuan dari penelitian ini antara lain:

1. Dapat meginterpretasi hasil bacaan instrumentasi pada tiang bor pada kasus ini.

2. Dapat mengetahui bagaimana kondisi tiang dengan melakukan pengujian laboratorium.

3. Dapat menduga penyebab kegagalan tiang bor pada kasus ini berdasarkan analisis-analisis yang dilakukan.

\section{TINJAUAN PUSTAKA}

\section{Vibrating Wire Strain Gauges (VWSG)}

VWSG merupakan instrumentasi yang dipasang pada tiang uji yang bertujuan untuk mengukur regangan yang dimana regangan yang didapatkan dapat mengetahui besar distribusi beban pada setiap kedalaman tiang (Ayal, 2015). Gaya beban yang didapatkan dari regangan dapan menggunakan persamaan

$$
\mathrm{Q}_{\mathrm{VWSG}}=\mathrm{A} \times \mathrm{Ex \varepsilon}
$$

dengan QvwsG = beban (ton), $\mathrm{A}=$ luas penampang $\left(\mathrm{m}^{2}\right), \mathrm{E}=$ modulus elastisitas beton $(\mathrm{Kpa}), \varepsilon=$ regangan

\section{Daya Dukung Tiang Secara Teoritis}

Daya dukung secara teoritis dapat berdasarkan parameter-parameter tanah yang sudah didapatkan. Untuk fondasi tiang bor, nilai Alpha yang sering digunakan adalah yang direkomendasikan oleh Rahardjo (2005). Nilainya umunnya berkisar antara 0.55-0.4. Dalam studi yang dilakukan penulis kali ini digunakan Alpha yaitu sama dengan 0.55. Untuk tanah non kohesif, Rahardjo mengusulkan nilai qp yang digunakan berdasarkan korelasi antara N-SPT dengan qp. Untuk tanah kohesif nilai qp dapat diperoleh dari 9 kali kuat geser tanah. Untuk tanah non kohesif nilai fs yang digunakan dapat diperoleh berdasarkan korelasi antara N-SPT dengan fs. Sedangkan untuk tanah kohesif nilai fs didapat dai nilai alpha dikalikan dengan kuat geser tanah.

Rahardjo merumuskan tahanan selimut tiang dengan menggunakan persamaan

$$
\mathbf{f s}=\alpha \mathbf{x} \mathbf{S u}
$$

Rahardjo merumuskan daya dukung ujung tiang dengan menggunakan persamaan

$$
\mathbf{Q p}=\mathbf{A p} \times \mathbf{q p}
$$

Rahardjo merumuskan daya dukung selimut tiang dengan menggunakan persamaan

$$
\text { Qs }=\text { As } x f s
$$

dengan $\mathrm{fs}=$ tahanan selimut $\left(\right.$ ton $\left./ \mathrm{m}^{2}\right), \alpha=$ faktor adhesi, $\mathrm{Su}=$ kuat geser tanah $\left(\mathrm{ton} / \mathrm{m}^{2}\right), \mathrm{Qp}=$ daya dukung ujung (ton), Ap = luas penampang tiang $\left(\mathrm{m}^{2}\right), \mathrm{qp}=$ tahanan ujung tiang $\left(\right.$ ton $\left./ \mathrm{m}^{2}\right)$, As $=$ luas selimut tiang $\left(\mathrm{m}^{2}\right)$. 


\section{Direct Shear Test}

Pada saat penggalian lubang bor, digunakan suatu polimer untuk memudahkan pengeboran dan menstabilkan lubang dari potensi longsor. Perilaku polimer dapat diuji dengan uji laboratorium direct shear. Polimer yang disarankan menurut brosur yang tertera pada lampiran adalah $0.05-0.2 \%$ dari volume air, sedangkan menurut para kontraktor disarankan polimer yang dipakai setidaknya 60s, dan tidak lebih dari 100s (Carlos dan Stephen, 2015). Untuk menaikan ph dari polimer, digunakan soda ash untuk membuat polimer menjadi basa dengan volume 0.5 gram berdasarkan brosur.

\section{METODOLOGI PENELITIAN}

\section{Metode Pengumpulan Data}

Metode yang digunakan dalam pengumpulan data-data yang akan dipakai adalah dengan pengumpulan data dari protek. Pada studi ini, data tanah yang dianalisis berlokasi di kawasan Sudirman Jakarta Selatan, DKI Jakarta. Data tanah berupa 13 boring log sedalam 100 meter, data 24 sondir, dan hasil tes laboratorium.

\section{Metode Analisis Data}

Sebelum dilakukannya analisis data, dilakukan pembelajaran atau studi tentang teori-teori dasar yang berhubungan dengan topik pembahasan dalam penelitian yang akan dilakukan. Teori dasar yang digunakan sebagai acuan pembelajaran dapat dicari berdasarkan berbagai macam sumber, seperti jurnal, karya ilmiah, buku referensi yang akan berguna untuk mendapatkan rumus-rumus atau persamaan dalam menghitung daya dukung pondasi tiang bor dan tata cara praktikum direct shear. Dalam melakukan analisis untuk daya dukung pondasi, metode analisis yang digunakan adalah dengan perhitungan manual yang mengacu pada parameter-parameter data tanah yang sudah didapatkan. Pengujian laboratorium direct shear mengacu pada ASTM D-3080-04.

\section{ANALISIS DAN PEMBAHASAN}

\section{Daya Dukung Tiang Bor Secara Teoritis}

Sebelum mencari daya dukung tiang, penentuan parameter tanah adalah hal penting yang harus dilakukan terlebih dahulu. Parameter tanah yang didapatkan berdasarkan korelasi (Budhu, 2015), pendekatan sesuai data boring log, sondir, dan data hasi pengujian laboratorium tersaji dalam tabel 1. Hasil daya dukung untuk tiang 72,7 meter dan diameter 1,2 meter tersaji dalam tabel 2 dan untuk grafik hubungan antara daya dukung dan kedalamannya dapat dilihat pada gambar 1 .

Tabel 1. Resume Parameter Tanah

\begin{tabular}{|c|c|c|c|c|c|c|c|c|c|}
\hline & $\begin{array}{l}\text { Kedalaman } \\
\text { (m) }\end{array}$ & Jenis Tanah & $\mathrm{N}$ & $\begin{array}{c}\text { Konsistensi } \\
\text { Tanah }\end{array}$ & Simbol & $\begin{array}{c}\mathrm{Su} \\
\left(\mathrm{kN} / \mathrm{m}^{2}\right)\end{array}$ & $\begin{array}{c}\gamma_{\text {sat }} \\
\left(\mathrm{kN} / \mathrm{m}^{3}\right)\end{array}$ & $\begin{array}{c}\phi \\
\left(^{\circ}\right)\end{array}$ & $\begin{array}{l}\text { PI } \\
(\%)\end{array}$ \\
\hline Lapisan 1 & $0-10$ & Silty Clay & 5 & Medium stiff & $\mathrm{CH}$ & 70 & 18 & 23 & 38 \\
\hline Lapisan 2 & $10-20$ & Silty Sand & 30 & Medium & SM & 250 & 19 & 35 & 38 \\
\hline Lapisan 3 & $20-25$ & Silty Sand & 20 & Medium & SM & 210 & 20 & 35 & 38 \\
\hline Lapisan 4 & $25-40$ & Silty Clay & 20 & Very stiff & $\mathrm{CH}$ & 210 & 20 & 23 & 38 \\
\hline Lapisan 5 & $40-60$ & Silty Clay & 25 & Very stiff & $\mathrm{CH}$ & 300 & 20 & 23 & 31 \\
\hline Lapisan 6 & $60-80$ & Silty Clay & 25 & Very stiff & $\mathrm{CH}$ & 300 & 20 & 23 & 31 \\
\hline Lapisan 7 & $80-100$ & Silty Clay & 32 & Hard & $\mathrm{CH}$ & 275 & 20 & 23 & 31 \\
\hline Lapisan 8 & $100-120$ & Silty Clay & 25 & Very stiff & $\mathrm{CH}$ & 250 & 21 & 23 & 31 \\
\hline
\end{tabular}


Tabel 2. Daya Dukung Tiang Bor $72.7 \mathrm{~m}$ Diameter $1.2 \mathrm{~m}$

\begin{tabular}{cccccccccc}
\hline Depth $(\mathrm{m})$ & Titik & Segmen & Jenis Tanah & $\mathrm{L}(\mathrm{m})$ & As $\left(\mathrm{m}^{2}\right)$ & Su $\left(\right.$ ton $\left./ \mathrm{m}^{2}\right)$ & fs $\left(\right.$ ton $\left./ \mathrm{m}^{2}\right)$ & Qs (ton) & Q (ton) \\
\hline 1.9 & A & A-B & Silty Clay & 14.85 & 55.98 & 7 & 3.85 & 215.54 & 3175.93 \\
\hline 16.75 & B & B-C & Silty Sand & 14.05 & 52.97 & 25 & 6.4583 & 342.08 & 2960.40 \\
\hline 30.8 & C & C-D & Silty Clay & 2 & 7.54 & 21 & 11.55 & 87.08 & 2618.32 \\
\hline 32.8 & D & D-E & Silty Clay & 4 & 15.08 & 21 & 11.55 & 174.17 & 2531.23 \\
\hline 36.8 & E & E-F & Silty Clay & 4 & 15.08 & 21 & 11.55 & 174.17 & 2357.06 \\
\hline 40.8 & F & F-G & Silty Clay & 4 & 15.08 & 30 & 16.5 & 248.81 & 2182.89 \\
\hline 44.8 & G & G-I & Silty Clay & 8 & 30.16 & 30 & 16.5 & 497.63 & 1934.08 \\
\hline 52.8 & I & I-J & Silty Clay & 4 & 15.08 & 30 & 16.5 & 248.81 & 1436.45 \\
\hline 56.8 & J & J-K & Silty Clay & 4 & 15.08 & 30 & 16.5 & 248.81 & 1187.64 \\
\hline 60.8 & K & K-M & Silty Clay & 8 & 30.16 & 30 & 16.5 & 497.63 & 938.82 \\
\hline 68.8 & M & M-N & Silty Clay & 3.9 & 14.70 & 30 & 16.5 & 242.59 & 441.19 \\
\hline 72.7 & N & & & & & & & 198.60 \\
\hline
\end{tabular}

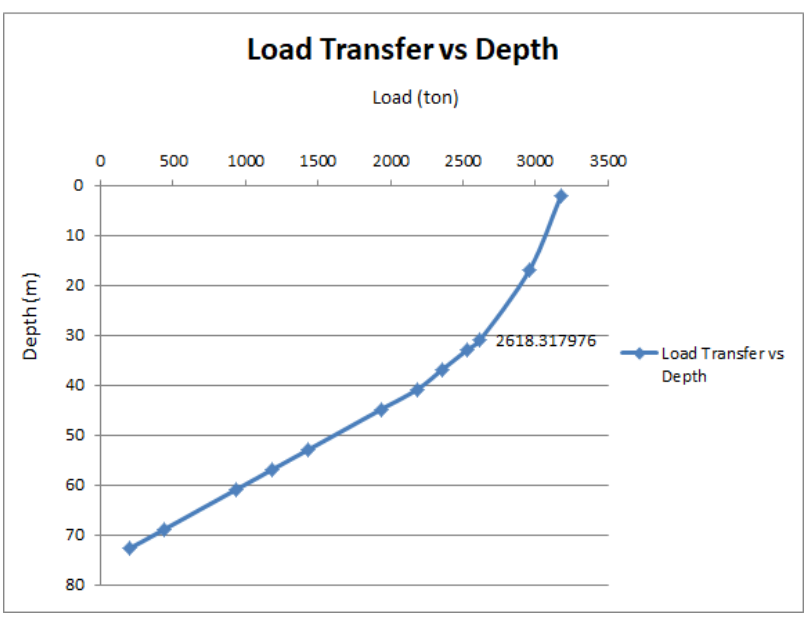

Gambar 1. Grafik Hubungan Kedalaman dan Load Transfer Tiang Bor 72.7m Berdiameter 1.2m

\section{Daya Dukung Tiang Bor Berdasarkan Bacaan VWSG}

Hasil daya dukung yang ditinjau berasal dari bacaan 3 test pile yaitu PTP 01, PTP 02, dan PTP 05. Masing-masing dilakukan pengetesan beban sebanyak 5 siklus. Data regangan yang didapat dari VWSG dan hasil dari gaya beban VWSG-nya (diambil contoh beban tertinggi) dan gambar grafik hubungan antara gaya beban dan kedalaman pada PTP 01 masing-masing tersaji pada tabel 3 dan gambar 2.

Tabel 3. QVWSG Cycle 51862 ton PTP 01

\begin{tabular}{cccc}
\hline Depth $(\mathrm{m})$ & $\begin{array}{c}\text { Titik Pemasangan } \\
\text { VWSG }\end{array}$ & Strain & QVWSG (ton) \\
\hline 1.9 & $\mathrm{~A}$ & 584 & 1700.3 \\
\hline 16.75 & $\mathrm{~B}$ & 308 & 896.73 \\
\hline 30.8 & $\mathrm{C}$ & 256 & 745.33 \\
\hline 32.8 & $\mathrm{D}$ & 244 & 710.4 \\
\hline 36.8 & $\mathrm{E}$ & 209 & 608.5 \\
\hline 40.8 & $\mathrm{~F}$ & 193 & 561.91 \\
\hline 44.8 & $\mathrm{G}$ & 155 & 451.28 \\
\hline 52.8 & $\mathrm{I}$ & 100 & 291.15 \\
\hline 57 & $\mathrm{~J}$ & 83 & 241.65 \\
\hline 60.8 & $\mathrm{~K}$ & 96 & 279.5 \\
\hline 68.8 & $\mathrm{M}$ & 96 & 279.5 \\
\hline 72.7 & $\mathrm{~N}$ & 146 & 425.07 \\
\hline
\end{tabular}




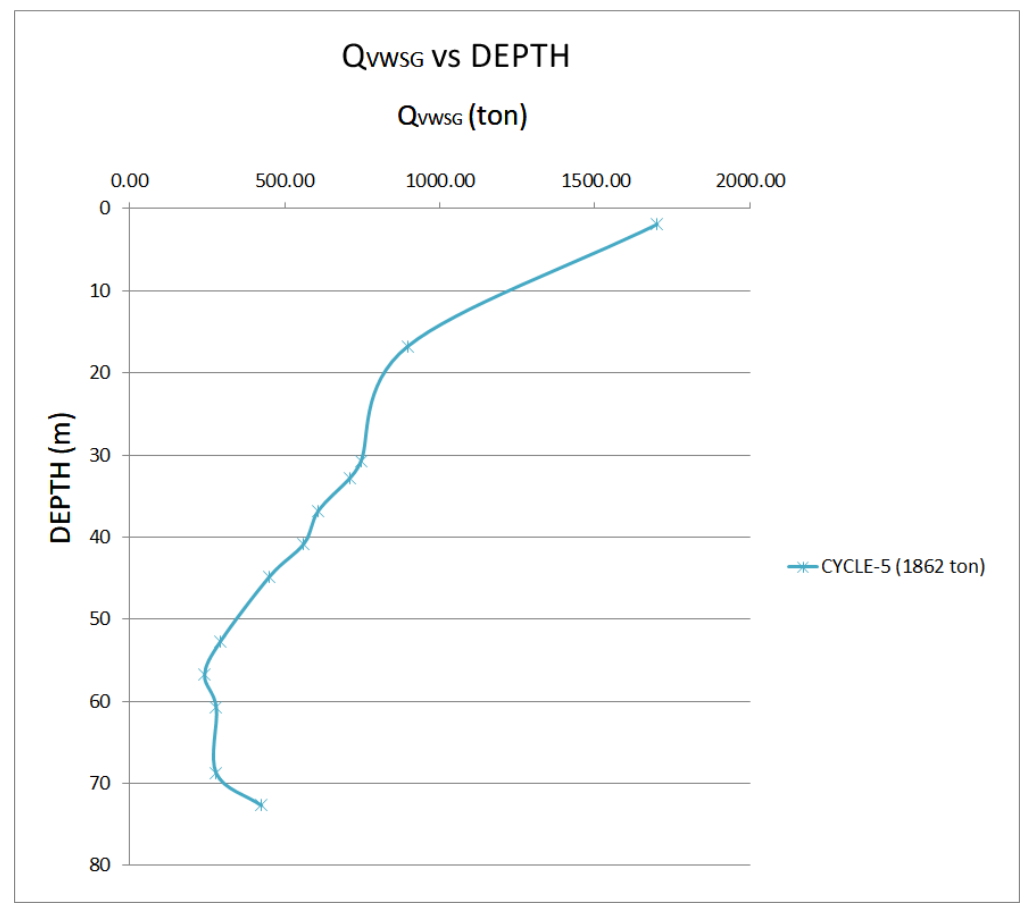

Gambar 2. Grafik Hubungan Antara Gaya Beban VWSG Cycle 51862 ton PTP 01 dan Kedalaman

Setelah didapatkan hasil beban VWSG untuk PTP 01, 02, dan 05, beban tersebut dibandingkan dengan grafik beban secara teoritis manual yang tersaji pada gambar 3 .

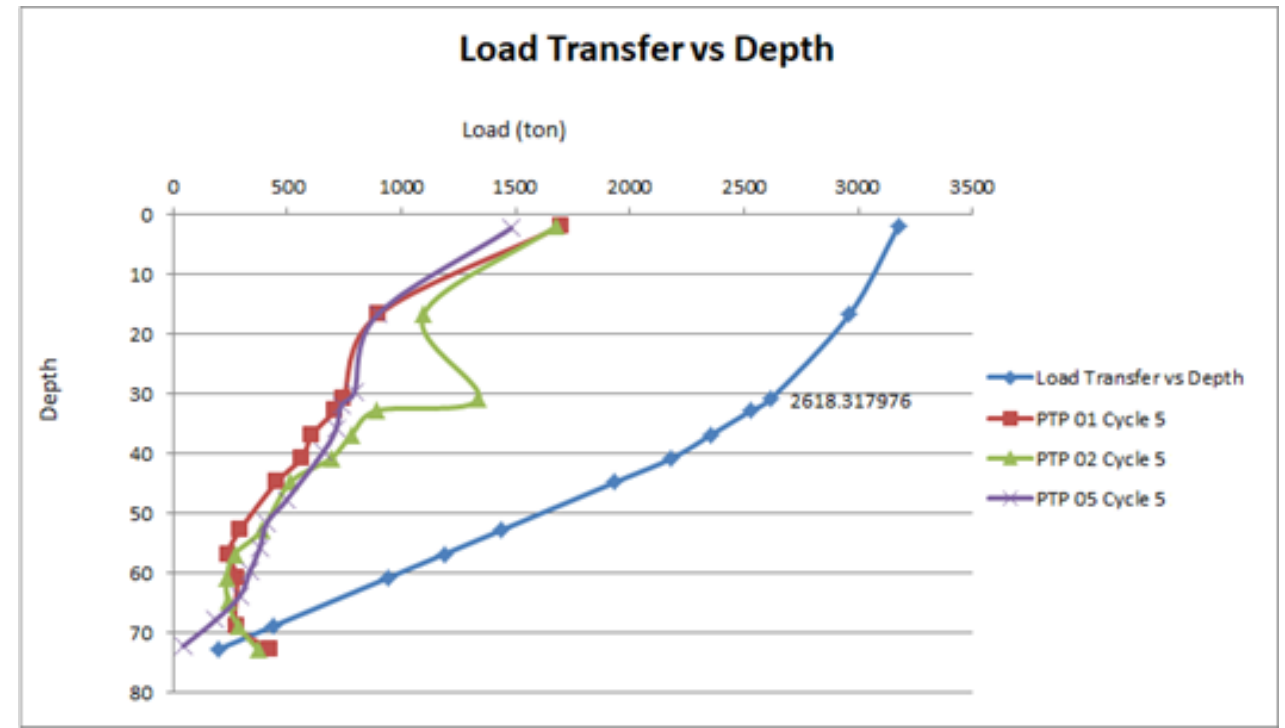

Gambar 3. Grafik Perbandingan Antara Load Transfer vs Depth Secara Teoritis dengan Load Transfer vs Depth Berdasarkan Test Pile Terinstrumen PTP 01, 02, dan 05

\section{Percobaan Direct Shear}

Pengambilan sampel di lokasi proyek pada saat sedang dilakukannya pengeboran, diambil sampel tanah di kedalaman 31 meter. Sampel tanah di cetak dengan alat CBR sesuai dengan tegangan di kedalaman tersebut. Kemudian sampel tanah disimpan dalam plastik agarkadar air tidak berubah.

Polimer yang digunakan untuk diuji adalah polimer dengan viskositas $165 \mathrm{MEV}$, viskositas dari polimer diukur dengan menggunakan marsh funnel dan didapatkan waktu 165 detik untuk polimer tersebut habis melewati lubang. Kemudian sampel tanah tadi agar tidak berantakan saat ditekan dengan pipa pencetak, sampel di tekan kembali dengan alat CBR agar mudah dicetak ke dalam pipa yang seukuran dengan mold direct shear. selanjutnya polimer dituang kedalam pipa yang berisi sampel tanah kemudian diamkan semalaman, keesokan harinya suntik beton kedalam polimer, atur hingga selang bersentuhan dengan tanah kemudian mulai menyuntik hingga sesuai dengan ketinggian beton yang diinginkan. Setelah beton mengering terlihat bahwa beton menjadi berkapur, rapuh dan retak- 
retak yang akhirnya menjadi hancur sebelum sampel dilakukan pengetesan direct shear dimana foto sampel dapat dilihat pada gambar 4.

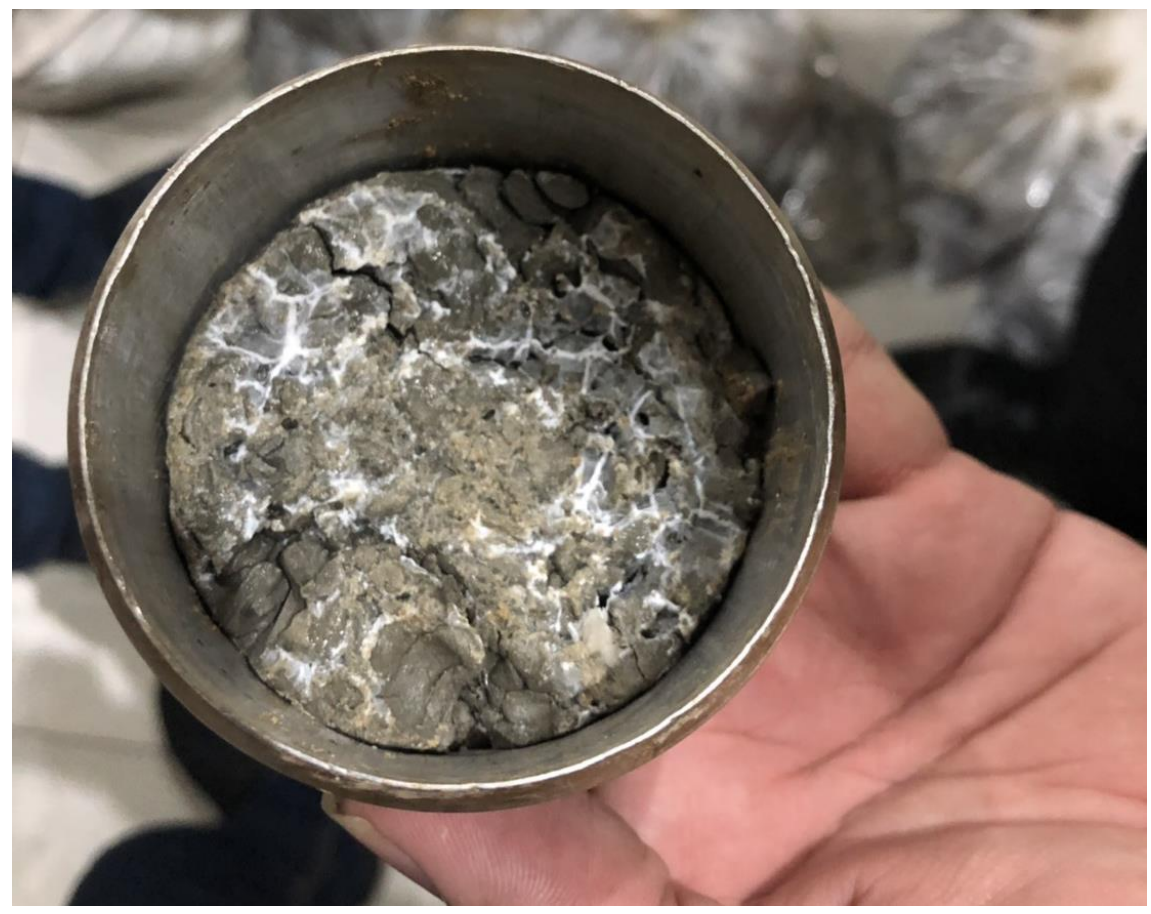

Gambar 4. Hasil Beton Pada Sampel Dengan Polimer 165MEV yang Menjadi Retak-Retak dan Terlihat Rapuh

\section{KESIMPULAN}

Berdasarkan analisis yang dilakukan, didapatkan beberapa kesimpulan sebagai berikut:

1. Berdasarkan resume parameter yang didapatkan, data tanah pada lokasi proyek kasus ini terbagi menjadi delapan lapisan, dengan jenis tanah silty clay untuk lapisan 1, 4-8, dan silty sand untuk lapisan 2 dan 3.

2. Berdasarkan grafik perbandingan antara load transfer $v$ s depth secara teoritis dengan load transfer vs depth berdasarkan test pile VWSG, terlihat daya dukung menurut bacaan VWSG yang lebih kecil.

3. Dapat diduga kemungkinan penyebab drop-nya tiang bor pada proyek ini adalah akibat dari pelaksanaan nya karena pemakaian polimer di atas batas yang disarankan, karena berdasarkan pengujian lab yang dilakukan dengan polimer yang tinggi, beton menjadi rapuh dan rusak. Polimer bersifat basa dapat kembali lagi menjadi air karena mengambil sebagian kalsium dari beton, akibatnya mutu beton menjadi menurun karena kalsium merupakan unsur penting dalam beton.

\section{DAFTAR PUSTAKA}

Ayal, M.E. (2015). Studi Mekanisme Transfer Beban Pada Tiang Bor Berinstrumen Berdasarkan Uji Laboratorium Dan Data Lapangan. Jurnal Teknologi. Vol. 12. No. 2 (Oktober 2015): 2087-2096.

Budhu, M. (2015). Soil Mechanics Fundamentals Imperial version. New York: John Wiley \& Sons.

Carlos, L. dan Stephan A.J. (2015). Performance of Bored Piles Construction Using Polymer Fluids: Lesson from European Experience. Journal of Performance of Constructed Facilities (Juli 2015).

Rahardjo, P.P. (2005). Manual Pondasi Tiang Edisi 3. Bandung: Publikasi GEC, Universitas Katolik Parahyangan. 